\title{
Eliminating Perceived Stigma and Burnout among Nurses Treating HIV/AIDS Patients Implementing Integrated Intervention
}

\author{
Ilakkiya. $\mathrm{L}^{1 *}$, Dr S. Subramanian ${ }^{2}$
}

\section{ABSTRACT}

Stigma is essentially one of the most important barriers to public action, disease disclosure and treatment adherence, worse even it gets exacerbated when those who provide treatment hold stigmatizing attitudes or at the receiving end of stigma. Stigma is of global concern and it requires an intensive integrated approach across all levels to eliminate it from healthcare settings for the betterment of patients and nurses. Objective: The present study intended to explore whether there were significant association between Perceived Stigma and Burnout Syndrome among nurses treating cancer patients and nurses treating HIV/AIDS patients and the extent to which the Integrated Intervention facilitates eliminating Perceived Stigma and Burnout. Methods: Around 120 nurses treating HIV/AIDS patients were selected from a sample of 240 nurses working in government hospitals in Chennai. Later, the Nurses were classified into two groups - as Experimental Group $(\mathrm{N}=30)$ and Control Group $(\mathrm{N}=30)$ treating HIV/AIDS patients in Government Hospitals. Their level of Perceived Stigma was measured using the HASI-N developed by Uys and others and burnout level was assessed using questionnaire developed by Maslach. The comprehensive Integrated Intervention covering cognitive restructuring, Jacobson's Progressive Muscle Relaxation, yoga and mindfulness meditation, etc was administered exclusively to the Experimental Group of Nurses for the duration of three months. The required data on Perceived Stigma and Burnout levels were measure at three phases of time period - pre and post period of the administration of Integrated Intervention. Results: In this study, these two categories of nurses were tested at three points of time (pre-test, post-test and follow-up). The within-subjects factor was the three phases of testing (pre-test, post-test, and follow-up) of the variables under investigation or time and the between-subjects factor was the two Category of nurses. Therefore, a mixed model factorial ANOVA was used to analyse differences over time and between the two categories of nurses Conclusions: There were significant differences among nurses treating HIV/AIDS patients with regard to stigma and burnout.

Keywords: Stigma, burnout, Nurses, HIV/AIDS, Patients,

\footnotetext{
${ }^{1}$ Ph.D, Research scholar, Dept. of Psychology, Bharathiar University Coimbatore

${ }^{2}$ Professor and Head of the Department, Dept. of Psychology, Bharathiar University

*Responding Author (C) 2016 I L Ilakkiya, S Subramanian; licensee IJIP. This is an Open Access Research distributed under the terms of the Creative Commons Attribution License (http://creativecommons.org/licenses/by/2.0), which permits unrestricted use, distribution, and reproduction in any Medium, provided the original work is properly cited.
} 


\section{Eliminating Perceived Stigma and Burnout among Nurses Treating HIV/AIDS Patients Implementing Integrated Intervention}

The concept of stigma is derived from the work of Goffman who referred to it as an attribute that is deeply discrediting and that reduces the discredited from a whole and usual person to a tainted, discounted one (Goffman, 1963). It is reported by UNAIDS (2008) that HIV/AIDS is one of the most destructive epidemics ever documented in the history claiming lives of more than 25 million people. In the world, HIV epidemic is rising at a considerable rate with high proportion of new HIV infected individuals and AIDS deaths. Globally, 30 to 36 million individuals were infected with HIV (UNAIDS, 2008). India has the highest number of Persons Living with HIV/AIDS (PLWHA) in the world today although the overall prevalence remains low. There are more than 5.1 million people who are infected with HIV in India. In spite of recent improved access to advanced treatment and care, AIDS has claimed an estimated population of 2.8 million across the world. Tamilnadu is one of the most prevalence states of South India accounting for $57 \%$ of all HIV infections in the country (INDIA FACTS, 2012).

\section{Stigma}

Herek (1999) defined HIV/AIDS related stigma as prejudice, discounting, discrediting, and discrimination directed at people perceived to have AIDS. Stigma is often associated with discrimination and human right and has been defined in various ways. The concept of stigma gains much more significance in the context of treating or attending to PLHIV since these diseases and more often people suffering from such diseases are targets of negative attitudes from the society in general. Enacted as well as felt stigma for nurses and for the patients they are attending to can be detrimental to disease outcomes as well as care giving.

\section{Burnout}

Burnout was predominantly with reference to work in human services, such as health care, social work, psychotherapy, legal services, and police work. Burnout is a major problem for professions that include human services and socially committed job like nurses, social workers, doctors and police. Nurses are mainly a focused group as they are the most vulnerable of all and are reported to have more burnout due to the nature of their work.

\section{Integrated Intervention}

The causes and negative consequences of perceived stigma and burnout among nurses are well known, less is known about the effective ways to reduce or prevent this growing problem. Mindfulness meditation, Jacobson's progressive muscle relaxation, yoga and cognitive restructuring is known to be effective in reducing stress and burnout and improving mental health of nurses who treat HIV/AIDS patients.

\section{Mindfulness Meditation}

Mindfulness Meditation is a non-sectarian, research based form of meditation. The roots of Mindfulness Meditation list in the 2,500 year old Buddhist meditation practice called Vipassana or Insight Meditation. It is a form of meditation that is designed to develop the skill of paying 


\section{Eliminating Perceived Stigma and Burnout among Nurses Treating HIV/AIDS Patients Implementing Integrated Intervention}

attention to an individual's inner and outer experiences with acceptance, patience, and compassion. Mindfulness meditation is a type of mental training.

\section{Yoga}

The word yoga means 'unity' or 'oneness' and is derived from the Sanskrit word 'yuj' which means 'to join'. It is a combination of physical and mental disciplines which make the body stronger and healthier and the mind calmer and more controlled, helping towards self-realization. The practice of physical postures known as asanas helps to purify the body and provide physical strength, stamina, tones the internal organs, improves concentration, flexibility and suppleness.

\section{Jacobson's Progressive Muscle Relaxation (JPMR)}

Jacobson's Progressive Muscle Relaxation was first used and introduced Edmund Jacobson in 1929 to treat anxiety in his patients. It is also known as progressive relaxation therapy; therapy that focuses on tightening and relaxing specific muscle groups in sequence. Through tensing and then relaxing specific muscles, the individual becomes more aware of bodily sensations. It is a well-known fact that stress and anxiety cause muscular tension. Regular practice of relaxation techniques can have a wide range of health benefits. It can relieve anxiety, stress, and lower blood pressure and reduce insomnia.

\section{Cognitive Restructuring}

Cognitive restructuring was initially developed by psychologist Aaron Beck and Albert Ellis in the mid-1950s as a part of their Cognitive Behavioral Therapy and Rational Emotive behavioral Therapy respectively. It is a very powerful technique that helps individuals cope with stressful situations by controlling and changing their negative thoughts, which are at times, results in damaging behaviors.

\section{AIM OF THE STUDY}

This study intended to study the relationship between Stigma and Burnout Syndrome among nurses treating cancer patients and nurses treating HIV/AIDS patients and the extent to which the Integrated Intervention facilitates eliminating Perceived Stigma and Burnout.

\section{METHODS}

\section{Hypotheses}

$\mathbf{H}_{1}$ : There will be a significant relationship between Stigma and Burnout Syndrome among nurses treating PLHIV.

$\mathbf{H}_{2}$ : The Experimental Group of nurses (treating HIV/AIDS patients) who have been exposed to the Integrated Intervention will show more reductions in Stigmatizing Patients dimension of Perceived Stigma than the Control Group from pretest to posttest. 


\section{Eliminating Perceived Stigma and Burnout among Nurses Treating HIV/AIDS Patients Implementing Integrated Intervention}

$\mathbf{H}_{3}$ :The Experimental Group of nurses (treating HIV/AIDS patients) who have been exposed to the Integrated Intervention will show more reductions in Being Stigmatized dimension of Perceived Stigma than the Control Group from pretest to posttest.

$\mathbf{H}_{4}$ : The Experimental Group of nurses (treating HIV/AIDS patients) who have been exposed to the Integrated Intervention will show more reductions in Emotional Exhaustion dimension of Burnout than the Control Group from pretest to posttest.

$\mathbf{H}_{5}$ :The Experimental Group of nurses (treating HIV/AIDS patients) who have been exposed to the Integrated Intervention will show more improvements in depersonalization on of Burnout than the Control Group from pretest to posttest.

$\mathbf{H}_{6}$ : The Experimental Group of nurses (treating HIV/AIDS patients) who have been exposed to the Integrated Intervention will show more improvements in Personal Achievement dimension of Burnout than the Control Group from pretest to posttest.

\section{Sampling}

Around 120 nurses treating HIV/AIDS patients were selected from a sample of 240 nurses working in government hospitals in Chennai. Later, the Nurses were classified into two groups as Experimental Group ( $\mathrm{N}=30)$ and Control Group $(\mathrm{N}=30)$ treating HIV/AIDS patients in Government Hospitals.

\section{Measures}

The following instruments were used to collect data from the sample:

1. Stigma: HIV/AIDS STIGMA INSTRUMENT - NURSE (HASI-N) (Uys et al., 2009). HASI-N is a 19-item instrument composed of two factors: Nurses Stigmatizing Patients (10 items) and Nurses Being Stigmatized (9 items). HASI-N, participants were asked to mark how often they had observed an event during the past 3 months ( 0 [never], 1 [once or twice], 2 [several times], or 3[most of the time]). The responses for each item are summed and then divided by the number of items in the factor or the instrument as a whole, with resulting scores ranging from 0 to 3 . The higher the score, the higher is the level of perceived HIV stigma. It is the first inductively derived instrument measuring stigma experienced and enacted by nurses. The internal consistency of the scale was .93

2. Burnout: The Maslach Burnout Inventory (MBI) (Maslach \& Jackson, 1981) was used to measure respondents' perceived experience of burnout in relation to the recipients of their service, care or treatment. The MBI consists of 22 items phrased as statements about personal feelings and attitudes, which is self-scored on a seven-point frequency scale, ranging from 0 (never) to 6 (every day). Burnout is measured along three dimensions such as Emotional Exhaustion, Depersonalization and Personal Accomplishment.

Internal Consistency was estimated by Cronbach's alpha coefficient. The reliability co-efficient for the subscales of Maslach's Burnout Inventory are given below 


\begin{tabular}{|l|l|}
\hline Sub Scale & Cronbach's alpha \\
\hline Emotional Exhaustion & .801 \\
\hline Depersonalization & .754 \\
\hline Personal Achievement & .722 \\
\hline
\end{tabular}

\section{RESULTS AND DISCUSSION}

Table 1, Descriptive Statistics for Stigmatizing Patients and Being Stigmatized for the two categories of nurses at the three stages of testing

\begin{tabular}{|l|l|l|l|}
\hline \multirow{2}{*}{ Dimension / Category } & \multicolumn{2}{|l|}{$\begin{array}{l}\text { Mean } \\
\text { SD }\end{array}$} & \multicolumn{2}{|l|}{} \\
\cline { 2 - 4 } & Pretest & Posttest & Follow up \\
\hline Stigmatizing Patients & & & \\
\hline Experimental Group - HIV/AIDS & 1.35 & 0.63 & 0.58 \\
& 0.65 & 0.39 & 0.35 \\
\hline Control Group - HIV/AIDS & 1.16 & 1.17 & 1.20 \\
& 0.65 & 0.59 & 0.52 \\
\hline Being Stigmatized & & & \\
\hline Experimental Group - HIV/AIDS & 1.23 & 1.27 & 1.25 \\
& 0.53 & 0.40 & 0.39 \\
\hline Control Group - HIV/AIDS & 1.06 & 1.09 & 1.10 \\
& 0.51 & 0.45 & 0.43 \\
\hline
\end{tabular}

\section{Main Effects for Perceived Stigma Dimensions}

The results of the Mixed ANOVA for the two categories of nurses on Perceived Stigma and its dimensions are discussed below. The results of the multivariate tests indicated that there was a significant within-subjects effects (Pillai's Trace) $(\mathrm{V}=0.433, \mathrm{~F}=21.608, \mathrm{p}<.05)$ as well as significant time $\mathrm{X}$ category interaction effect $(\mathrm{V}=0.606, \mathrm{~F}=7.274, \mathrm{p}<.05)$ on Perceived Stigma.

Mauchly's test indicated that the assumption of sphericity had been violated for Stigmatizing Patients $\left(\chi^{2}=132.76, \mathrm{p}<.05\right)$ and Being Stigmatized $\left(\chi^{2}=70.29, \mathrm{p}<.05\right)$, therefore, the degrees of freedom were corrected using Greenhouse-Geisser estimates of sphericity.

Within-subjects effects indicated that there was main effects for time (pre-testing, post-testing and follow-up) or the three phases of testing on Stigmatizing Patients $(F=72.547, p<.05)$. Additionally there was a significant Time $\mathrm{X}$ Category interaction effect for Stigmatizing patients $(\mathrm{F}=34.253, \mathrm{p}<.05)$. However, there were no main effects for time on Being Stigmatized $(\mathrm{F}=$ $.054, \mathrm{p}>.05)$ and no significant interactions effects on Being Stigmatized ( $F=1.805, \mathrm{p}>.05)$.

The between-subject effects indicated that there was a significant category difference for Stigmatizing Patients $(\mathrm{F}=12.923, \mathrm{p}<.05)$. Stigmatizing Patients dimension is further investigated 
for simple main effects using repeated measures of ANOVA and one way ANOVAs for the three stages of testing (pre-testing, post-testing and follow-up) among the two categories of nurses.

\section{Simple Effects for Experimental Group of HIV/AIDS Treating Nurses on Stigmatizing Patients}

Simple main effects for category of Experimental group of HIV/AIDS treating nurses revealed that there were significant differences over time (pre-testing, post-testing and follow-up) ( $\mathrm{F}=$ 55.09, $\mathrm{p}<.05$ ). Tests of Within-Subjects Contrasts revealed that there was significant difference from pretest to posttest $\left(\mathrm{F}=51.708, \mathrm{p}<.05, \eta_{\mathrm{p}}{ }^{2}=.641\right)$ with a large effect size and from posttest to follow up ( $\left.\mathrm{F}=10.545, \mathrm{p}<.05, \eta_{\mathrm{p}}{ }^{2}=.267\right)$ with a large effect size

Table 2, Bonferroni Corrected Pair Wise Comparisons for Experimental Group of HIV/AIDS Treating Nurses on Stigmatizing Patients

\begin{tabular}{|l|l|l|l|}
\hline Measure & $(\mathbf{I})$ Time & $($ J) Time & Mean Difference (I-J) \\
\hline Stigmatizing Patients & Pretest & Posttest & $.717^{*}$ \\
\cline { 3 - 4 } & & Follow Up & $.770^{*}$ \\
\cline { 2 - 4 } & \multirow{2}{*}{ Posttest } & Pretest & $-.717^{*}$ \\
\cline { 3 - 4 } & & Follow Up & $.053^{*}$ \\
\hline
\end{tabular}

Simple Effects for Control Group of HIV/AIDS Treating Nurses on Stigmatizing Patients Simple main effects for category of Control group of HIV/AIDS treating nurses revealed that there were simple main effects for Stigmatizing Patients for the control group of HIV/AIDS treating nurses $(\mathrm{F}=0.566, \mathrm{p}>.05)$.

Further, between category comparisons among the two categories of nurses at the posttest and follow up stages revealed that there were significant differences at the posttest stage ( $F=16.647$, $\mathrm{p}<.05)$ and significant differences at the follow up stage $(\mathrm{F}=24.436, \mathrm{p}<.05)$. Duncan's post hoc homogeneous subsets revealed the following category groupings at the three stages of testing

Table 3, Duncan Post Hoc Homogeneous Subsets at the Pretest Stage for the two Categories of Nurses on Stigmatizing Patients

\begin{tabular}{|l|l|l|}
\hline Category & N & Subset 1 \\
\hline Control HIV/AIDS & 60 & 1.1640 \\
\hline Experimental HIV/AIDS & 60 & 1.3500 \\
\hline
\end{tabular}


Eliminating Perceived Stigma and Burnout among Nurses Treating HIV/AIDS Patients Implementing Integrated Intervention

Table 4, Duncan Post Hoc Homogeneous Subsets at the Posttest Stage for the two Categories of Nurses on Stigmatizing Patients

\begin{tabular}{|l|l|l|l|}
\hline Category & N & Subset 1 & Subset 2 \\
\hline Experimental HIV/AIDS & 60 & .6333 & \\
\hline Control HIV/AIDS & 60 & & 1.1700 \\
\hline
\end{tabular}

Table 5, Duncan Post Hoc Homogeneous Subsets at the Follow up Stage for the two Categories of Nurses on Stigmatizing Patients

\begin{tabular}{|l|l|l|l|}
\hline Category & $\mathbf{N}$ & Subset 1 & Subset 2 \\
\hline Experimental HIV/AIDS & 60 & .5800 & \\
\hline Control HIV/AIDS & 60 & & 1.1967 \\
\hline
\end{tabular}

\section{BURNOUT}

Table 6, Descriptive Statistics for Burnout Dimensions for the two categories of nurses at the three stages of testing (pre-testing, post-testing and follow-up) - Integrated Intervention

\begin{tabular}{|c|c|c|c|}
\hline \multirow[t]{2}{*}{ Dimension / Category } & \multicolumn{3}{|l|}{$\begin{array}{l}\text { Mean } \\
\text { SD }\end{array}$} \\
\hline & Pretest & Posttest & Follow up \\
\hline \multicolumn{4}{|l|}{ Emotional Exhaustion } \\
\hline Experimental Group - HIV/AIDS & $\begin{array}{l}25.70 \\
4.74\end{array}$ & $\begin{array}{l}23.70 \\
4.12\end{array}$ & $\begin{array}{l}23.03 \\
4.10\end{array}$ \\
\hline Control Group - HIV/AIDS & $\begin{array}{l}22.00 \\
9.01\end{array}$ & $\begin{array}{l}25.43 \\
5.70\end{array}$ & $\begin{array}{l}27.60 \\
3.87\end{array}$ \\
\hline \multicolumn{4}{|l|}{ Depersonalization } \\
\hline Experimental Group - HIV/AIDS & $\begin{array}{l}14.07 \\
2.59\end{array}$ & $\begin{array}{l}10.70 \\
2.64\end{array}$ & $\begin{array}{l}9.83 \\
2.28\end{array}$ \\
\hline Control Group - HIV/AIDS & $\begin{array}{l}12.33 \\
4.71\end{array}$ & $\begin{array}{l}15.10 \\
3.27\end{array}$ & $\begin{array}{l}16.30 \\
3.09\end{array}$ \\
\hline \multicolumn{4}{|l|}{ Personal Achievement } \\
\hline Experimental Group - HIV/AIDS & $\begin{array}{l}24.00 \\
5.26\end{array}$ & $\begin{array}{l}24.07 \\
3.62\end{array}$ & $\begin{array}{l}24.87 \\
3.07\end{array}$ \\
\hline Control Group - HIV/AIDS & $\begin{array}{l}24.63 \\
9.73\end{array}$ & $\begin{array}{l}23.07 \\
6.34\end{array}$ & $\begin{array}{l}22.87 \\
4.81\end{array}$ \\
\hline
\end{tabular}

\section{Main Effects for Burnout dimensions}

The results of the Mixed ANOVA for the two categories of nurses on Burnout dimensions are discussed below. The results of the multivariate tests indicated that there was a significant within-subjects effects (Pillai's Trace) $(\mathrm{V}=0.124, \mathrm{~F}=2.607, \mathrm{p}<.05)$, and significant time $\mathrm{X}$ category interaction effects were present $(\mathrm{V}=0.978, \mathrm{~F}=9.110, \mathrm{p}<.05)$. 


\section{Eliminating Perceived Stigma and Burnout among Nurses Treating HIV/AIDS Patients Implementing Integrated Intervention}

Mauchly's test indicated that the assumption of sphericity had been violated for Emotional Exhaustion $\left(\chi^{2}=113.55, \mathrm{p}<.05\right)$, Depersonalization $\left(\chi^{2}=27.82, \mathrm{p}<.05\right)$ and Personal Achievement $\left(\chi^{2}=32.36, \mathrm{p}<.05\right)$. Therefore, the degrees of freedom were corrected using Greenhouse-Geisser estimates of sphericity.

Within-subjects effects indicated that there was a significant main effects for time or the three phases of testing (pre-testing, post-testing and follow-up) on Emotional Exhaustion ( $F=4.734$, $\mathrm{p}<.05)$ and Depersonalization $(\mathrm{F}=3.646, \mathrm{p}<.05)$. Moreover, there were significant Time $\mathrm{X}$ Category interaction effects for Emotional Exhaustion $(\mathrm{F}=26.63, \mathrm{p}<.05)$ and Depersonalization $(\mathrm{F}=34.821, \mathrm{p}<.05)$. However there were no main effects $(\mathrm{F}=0.816, \mathrm{p}>.05)$ as well as Time $\mathrm{X}$ Category interaction effects $(\mathrm{F}=1.333, \mathrm{p}>.05)$ on Personal Achievement.

The results revealed that there was a significant between-subjects main effects for Emotional Exhaustion $(\mathrm{F}=7.008, \mathrm{p}<.05)$ and Depersonalization $(\mathrm{F}=7.091, \mathrm{p}<.05)$ and not for Personal Achievement $(\mathrm{F}=.231, \mathrm{p}>.05)$. Therefore, these two dimensions are further investigated for simple main effects using repeated measures of ANOVA and one way ANOVAs for the three stages of testing (pre-testing, post-testing and follow-up) among the two categories of nurses.

\section{Simple Effects for Experimental Group of HIV/AIDS Treating Nurses on Emotional Exhaustion and Depersonalization}

There were significant main effects for time (pre-testing, post-testing and follow-up) ( $\mathrm{F}=33.363$, $\mathrm{p}<.05$ ) on Emotional Exhaustion and no significant main effects for time (pre-testing, posttesting and follow-up) $(\mathrm{F}=51.208, \mathrm{p}<.05)$ on Depersonalization.

Tests of within-subjects contrasts revealed that there were significant differences from pretest to posttest ( $\left.\mathrm{F}=27.188, \mathrm{p}<.05, \eta_{\mathrm{p}}{ }^{2}=.484\right)$ with a large effect size and from posttest to follow up ( $\mathrm{F}=$ 10.545, $\mathrm{p}<.05, \eta_{\mathrm{p}}{ }^{2}=.267$ ) with a large effect size for experimental group nurses treating HIV/AIDS patients on Emotional Exhaustion.

The contrasts also indicated that there were significant differences from pretest to posttest $(\mathrm{F}=$ 51.102, $\mathrm{p}<.05, \eta_{\mathrm{p}}{ }^{2}=.638$ ) with a large effect size and from posttest to follow up ( $\mathrm{F}=4.685$, $\left.\mathrm{p}<.05, \eta_{\mathrm{p}}^{2}=.139\right)$ with a large effect size for the experimental group of nurses treating HIV/AIDS patients on Depersonalization. 
Eliminating Perceived Stigma and Burnout among Nurses Treating HIV/AIDS Patients Implementing Integrated Intervention

Table 7, Bonferroni Corrected Pair Wise Comparisons for Experimental Group of HIV/AIDS Treating Nurses on Emotional Exhaustion and Depersonalization

\begin{tabular}{|l|l|l|l|}
\hline Measure & (I) Time & (J) Time & Mean Difference (I-J) \\
\hline Emotional Exhaustion & \multirow{2}{*}{ Pretest } & Posttest & $2.000^{*}$ \\
\cline { 3 - 4 } & & Follow up & $2.667^{*}$ \\
\cline { 2 - 4 } & \multirow{2}{*}{ Posttest } & Pretest & $-2.000^{*}$ \\
\cline { 2 - 4 } & & Follow up & $.667^{*}$ \\
\hline \multirow{2}{*}{ Depersonalization } & Pretest & Posttest & $3.367^{*}$ \\
\cline { 2 - 4 } & & Follow up & $4.233^{*}$ \\
\cline { 2 - 4 } & Posttest & Pretest & $-3.367^{*}$ \\
\cline { 2 - 4 } & & Follow up & $.867^{\mathrm{ns}}$ \\
\hline
\end{tabular}

Note: $* \mathrm{p}<.05$, ns - not significant

Simple Effects for Control Group of HIV/AIDS Treating Nurses on Emotional Exhaustion and Depersonalization

There were simple main effects of time (pre-testing, post-testing and follow-up) on Emotional Exhaustion $(\mathrm{F}=17.366, \mathrm{p}<.05)$ and Depersonalization $(\mathrm{F}=22.952, \mathrm{p}<.05)$.

Simple main effects for category Control group of HIV/AIDS treating nurses revealed there was a significant increase from pretest to posttest $\left(\mathrm{F}=15.744, \mathrm{p}<.05, \eta_{\mathrm{p}}{ }^{2}=.352\right)$ and from posttest to follow up $\left(\mathrm{F}=11.597, \mathrm{p}<.05, \eta_{\mathrm{p}}{ }^{2}=.286\right)$ on Emotional Exhaustion and a significant increase over time from pretest to posttest $\left(\mathrm{F}=18.845, \mathrm{p}<.05, \eta_{\mathrm{p}}{ }^{2}=.394\right)$ and from posttest to follow up $\left(\mathrm{F}=9.434, \mathrm{p}<.05, \eta_{\mathrm{p}}^{2}=.245\right)$ on Depersonalization.

Table 8, Bonferroni Corrected Pair Wise Comparisons for Control Group of HIV/AIDS Treating Nurses on Emotional Exhaustion and Depersonalization

\begin{tabular}{|l|l|l|l|}
\hline Measure & (I) Time & (J) Time & Mean Difference (I-J) \\
\hline Emotional Exhaustion & \multirow{2}{*}{ Pretest } & Posttest & $-3.433^{*}$ \\
\cline { 3 - 4 } & & Follow up & $-5.600^{*}$ \\
\cline { 2 - 4 } & \multirow{2}{*}{ Posttest } & Pretest & $3.433^{*}$ \\
\cline { 2 - 4 } & & Follow up & $-2.167^{*}$ \\
\hline \multirow{2}{*}{ Depersonalization } & \multirow{2}{*}{ Pretest } & Posttest & $-2.767^{*}$ \\
\cline { 2 - 4 } & & Follow up & $-3.967^{*}$ \\
\cline { 2 - 4 } & \multirow{2}{*}{ Posttest } & Pretest & $2.767^{*}$ \\
\cline { 2 - 4 } & & Follow up & $-1.200^{*}$ \\
\hline
\end{tabular}

Note: $* \mathrm{p}<.05$ 
One way ANOVA for the two categories of nurses at the three stages of testing (pre-testing, post-testing and follow-up) revealed that there were no significant category differences at the pretest stage for both Emotional Exhaustion $(\mathrm{F}=1.706, \mathrm{p}>.05)$ and Depersonalization $(\mathrm{F}=1.574$, $\mathrm{p}>$.05). However, there were significant category differences for Emotional Exhaustion levels and Depersonalization levels at the posttest and follow up stages of testing.

Table 9, Duncan Post Hoc Homogeneous Subsets at the Posttest Stage for the two Categories of Nurses on Emotional Exhaustion

\begin{tabular}{|l|l|l|l|}
\hline Category & N & Subset 1 & Subset 2 \\
\hline Experimental HIV/AIDS & 60 & & 23.7000 \\
\hline Control HIV/AIDS & 60 & & 25.4333 \\
\hline
\end{tabular}

Table 10, Duncan Post Hoc Homogeneous Subsets at the Follow up Stage for the two Categories of Nurses on Emotional Exhaustion

\begin{tabular}{|l|l|l|l|}
\hline Category & N & Subset 2 & Subset 2 \\
\hline Experimental HIV/AIDS & 60 & 23.0333 & \\
\hline Control HIV/AIDS & 60 & & 27.6000 \\
\hline
\end{tabular}

Table 11, Duncan Post Hoc Homogeneous Subsets at the Posttest Stage for the two Categories of Nurses on Depersonalization

\begin{tabular}{|l|l|l|l|}
\hline Category & N & Subset 1 & Subset 2 \\
\hline Experimental HIV/AIDS & 60 & 10.7000 & \\
\hline Control HIV/AIDS & 60 & & 15.1000 \\
\hline
\end{tabular}

Table 12, Duncan Post Hoc Homogeneous Subsets at the Follow up Stage for the two Categories of Nurses on Depersonalization

\begin{tabular}{|l|l|l|l|}
\hline Category & N & Subset 1 & Subset 2 \\
\hline Experimental HIV/AIDS & 60 & 9.8333 & \\
\hline Control HIV/AIDS & 60 & & 16.3000 \\
\hline
\end{tabular}

\section{REFERENCES}

Goffman, E. (1963). Stigma: Notes on the Management of Spoiled Identity. Prentice-Hall. ISBN: 0-671-62244-7.

Herek, G. M. (1999). The social construction of attitudes: Functional consensus and divergence in the US public's reactions to AIDS. In G. R. Maio\& J. M. Olson (Eds.), Why We Evaluate: Functions of attitudes. Lawrence Erlbaum: Mahwah, NJ.

India Facts.(2012). HIV AIDS Statistics India 2012 - India HIV AIDS State wise Statistics. Retrieved from: http://indiafacts.in/health/hivaids-statistics/

Jacobson, E., (1938). Progressive Relaxation, Chicago: University of Chicago Press. 
Eliminating Perceived Stigma and Burnout among Nurses Treating HIV/AIDS Patients Implementing Integrated Intervention

UNAIDS(2008).Report on the global HIV/AIDS epidemic. Executive summary: Switzerland. Retrieved from http://data.unaids.org/pub/GlobalReport/2008/JC1511GR08 /Executive Summary /en.pdf

How to cite this article: L Ilakkiya, S Subramanian (2016), Eliminating Perceived Stigma and Burnout among Nurses Treating HIV/AIDS Patients Implementing Integrated Intervention, International Journal of Indian Psychology, Volume 3, Issue 3, No. 7, DIP: 18.01.127/20160303, ISBN: 978-1-365-12175-3 